\title{
A three dimensional kinetic model for the formation of acrylamide in french fries with variable glucose and fructose content
}

Book or Report Section

Accepted Version

Balagiannis, D. P., Parker, J. K., Higley, J., Smith, G., Wedzicha, B. L. and Mottram, D. S. (2016) A three dimensional kinetic model for the formation of acrylamide in french fries with variable glucose and fructose content. In: Granvogl, M., Peterson, D. and Schieberle, P. (eds.) Browned Flavors: Analysis, Formation, and Physiology. ACS Symposium Series, Vol. 1237. ACS, pp. 67-79. ISBN 9780841231856 doi: https://doi.org/10.1021/bk-2016-1237.ch006 Available at https://centaur.reading.ac.uk/68246/

It is advisable to refer to the publisher's version if you intend to cite from the work. See Guidance on citing.

To link to this article DOI: http://dx.doi.org/10.1021/bk-2016-1237.ch006

Publisher: ACS

Publisher statement: This document is the Accepted Manuscript version of a Published Work that appeared in final form in Browned Flavors: Analysis, Formation, and Physiology, copyright (๑ American Chemical Society after peer review and technical editing by the publisher.

All outputs in CentAUR are protected by Intellectual Property Rights law, including copyright law. Copyright and IPR is retained by the creators or other 
copyright holders. Terms and conditions for use of this material are defined in the End User Agreement.

\section{www.reading.ac.uk/centaur}

\section{CentAUR}

Central Archive at the University of Reading

Reading's research outputs online 


\title{
A Three Dimensional Kinetic Model for the Formation of Acrylamide in French Fries with Variable Glucose and Fructose Content
}

\author{
Dimitrios P. Balagiannis, ${ }^{\dagger}, *$ Jane K. Parker, ${ }^{\dagger}$ Jeremy Higley, ${ }^{\ddagger}$ Gordon \\ Smith,,$\neq \#$ Bronislaw L. Wedzicha, ${ }^{\S}$ and Donald S. Mottram ${ }^{\dagger}$ \\ tDepartment of Food and Nutritional Sciences, University of Reading, \\ Whiteknights, Reading RG6 6AP, United Kingdom \\ ${ }^{\ddagger}$ ConAgra Foods, Six ConAgra Drive, Omaha, Nebraska 68102 \\ "Current address: Grain Science and Industry Department, Kansas State \\ University, Manhattan KS 66506 \\ \$School of Food Science and Nutrition, University of Leeds, Leeds LS2 9JT, \\ United Kingdom \\ *d.balagiannis@reading.ac.uk
}

For modeling and predicting the formation of acrylamide in real food systems, it is not only important to understand the underlying chemistry, but also the complex effects of heat and moisture transfer which means that in French fries, for example, most of the acrylamide is formed on the edges and corners of the fry. In this paper, simple approximations have been employed to build a mathematical model that approximates the heat and mass transport phenomena in three dimensions. It successfully predicts the concentration of acrylamide and its precursors at different positions in the 'fry'.

RESERVE THIS SPACE 


\section{Introduction}

Kinetic modelling is a very useful tool to study chemical reactions, particularly those as complex as the Maillard reaction. Many researchers have applied this approach to understand the kinetics of formation of acrylamide. Most of these studies have involved simple buffered model systems, covering a variety of precursors and simulated process conditions (1-2). Recently, Parker, et al. (3) reported the kinetics of acrylamide formation in standard commercial French fries with variable sugar content, taking into account moisture and heat transfer phenomena that occur within the potato during frying. They manipulated the initial sugar content by dipping the raw potato strips in aqueous solutions containing different levels of glucose or fructose. The fries were prepared using the standard industrial protocols and processed in a pilot-scale fryer for a series of different times and temperatures. Based on the chemistry of acrylamide formation, the authors proposed a multi-step kinetic mechanism and developed a mathematical model which accounted for the kinetics of acrylamide formation. The fit to the experimental data was excellent; however, that model was based on one-dimensional heat and mass transfer ignoring the transport phenomena coming from the other two dimensions. Hence it was missing important physicochemical interactions occurring at the edges and corners of the fries, a region where acrylamide formation is potentially high. In the improved model that is presented in this paper, the latter issue is resolved. Furthermore, a new rate constant $\mathrm{k}_{3}$ is introduced which accounts for the conversion of the second group of intermediates (Int2) to acrylamide and other Maillard products. The latest iteration was considered necessary in order to account better for the kinetics of the loss of asparagine and the total free amino acid during frying, as well as the corresponding predictive power for acrylamide formation.

\section{Materials and Methods}

The experimental procedure is described in detail in (3). Briefly, the 'fries' were prepared using a typical industrial process. After blanching, the potato strips were dipped in aqueous solutions with varying (0-5\%) glucose or fructose concentration so as to manipulate the sugar content of the strips which were subsequently par-fried.. The par-fried potato strips were frozen and finish fried for different times $(0-5 \mathrm{~min})$ at three temperatures $\left(165,175\right.$ and $\left.185{ }^{\circ} \mathrm{C}\right)$. The 'fries' were then analyzed for their moisture and fat content, the concentrations of glucose, fructose, acrylamide and free amino acids.. 


\section{Results and Discussion}

\section{Temperature profile/Heat transport model}

Finish frying of frozen par-fried potato strips takes place at high temperatures (typically $165-185{ }^{\circ} \mathrm{C}$ ) for short time (typically $2-5 \mathrm{~min}$ ). As a result, a temperature gradient is formed within the fries which is a function of processing time $(t)$ and distance $(x)$ from the surface of the fry that is in contact with the hot oil. Parker, et al. (3) introduced Equation 1 which accounted for the temperature variation across the fried potato strips. It was based on the study by $\mathrm{Ni}$ and Datta (4) who modelled the temperature gradient with respect to time and distance from the surface of a one-dimensional potato model.

Temp $=$ Temp $_{o}-\frac{780 x}{\left(-4.96 \times 10^{-5} t^{2}+9.81 \times 10^{-2} t+1.1657\right)}$

for Temp $>90^{\circ} \mathrm{C}$

where,

Temp: temperature $\left({ }^{\circ} \mathrm{C}\right)$ of the 'fry'

Temp : initial oil temperature $\left({ }^{\circ} \mathrm{C}\right)$

$x$ : distance from surface $(\mathrm{mm})$

$t$ : frying time (min)

\section{Moisture model}

During frying there is a constant evaporation from the surface of the 'fry' reducing the overall moisture from $\sim 70 \%$ to c. $30 \%$ after 5 minutes of processing. This creates two distinctive zones along the 'fry': a dry zone, where the moisture has evaporated, and a wet zone where limited evaporation or no evaporation has taken place. In the wet zone, a moisture gradient applies where moisture content increases gradually from the boundary with the dry zone towards the center of the 'fry'. During frying, a thin crust layer is being formed and the boundary between the two zones changes with time and moves towards the center. Hence, the moisture content is a function of the distance from the surface as well as the frying time. Parker, et al. (3), used the unidimensional potato model proposed by $\mathrm{Ni}$ and Datta (4) to suggested an equation which expressed the moisture content in potato strips during frying, accounting for moisture loss only in one dimension. For the present study, this equation was 
revised to include a more general term which also accounted for the processing temperature.

For the French fry illustrated in Figure 1, in order to estimate the moisture content of the cube with co-ordinates $\left(l_{1}, l_{2}\right)\left(h_{1}, h_{2}\right)\left(w_{1}, w_{2}\right)$ and using the one dimensional approach, the rate of change of moisture with respect to the $\mathrm{x}$-axis is given by Equation 2:

$\frac{d M_{x}}{d t}=-\frac{100}{60 A\left(l_{2}-l_{1}\right)}\left(\right.$ Temp $\left.p_{\text {oil }}-100\right) \int_{l_{1}}^{l_{2}} e^{-\frac{B x}{10}} d x$

where,

$M_{x}$ : moisture content $(\mathrm{g} / 100 \mathrm{~g})$

$l_{2}-l_{1}$ : length of any cube within the 'fry' ( $\left.\mathrm{mm}\right)$

$t$ : frying time (sec)

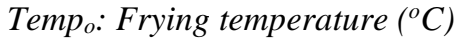

$A$ and B: Model parameters

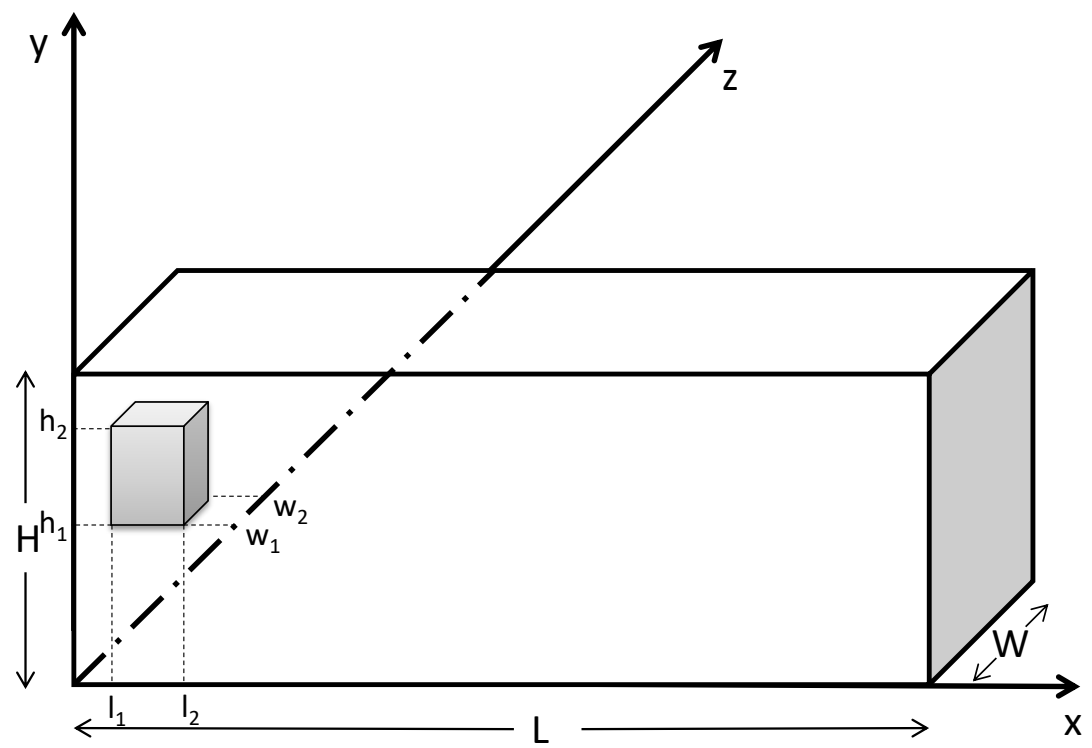

Figure 1 A hypothetical potato 'fry' on a Cartesian coordinate system

Similarly, on a one-dimensional basis, the moisture content with respect to the $y$ and $z$ axis is given by equations 3 and 4 : 


$$
\begin{aligned}
& \frac{d M_{y}}{d t}=-\frac{100}{60 A\left(h_{2}-h_{1}\right)}\left(\text { Temp }_{\text {oil }}-100\right) \int_{h_{1}}^{h_{2}} e^{-\frac{B y}{10}} d y \\
& \frac{d M_{z}}{d t}=-\frac{100}{60 A\left(w_{2}-w_{1}\right)}\left(\text { Temp } p_{\text {oil }}-100\right) \int_{w_{1}}^{w_{2}} e^{-\frac{B z}{10}} d z
\end{aligned}
$$

where

$h_{2}-h_{1}$ : height of any cube within the 'fry' $(\mathrm{mm})$

$w_{2}-w_{1}$ : width of any cube within the 'fry' $(\mathrm{mm})$

So, assuming moisture loss in one direction is independent of the loss in the other two, the rate of change of moisture in the 'fry' is:

$\frac{d M_{t o t}}{d t}=\frac{d M_{x}}{d t}+\frac{d M_{y}}{d t}+\frac{d M_{z}}{d t}$

Substituting for $d M_{x} / d t, d M_{y} / d t$ and $d M_{z} / d t$ and solving the differential equation, an approximate expression for the total moisture content $\left(M_{t o t}\right)$ of the cube with co-ordinates $\left(\mathrm{l}_{1}, \mathrm{l}_{2}\right)\left(\mathrm{h}_{1}, \mathrm{~h}_{2}\right)\left(\mathrm{w}_{1}, \mathrm{w}_{2}\right)$ is given by equation 6

$$
\begin{aligned}
& M_{\text {tot }}=M_{o}-\frac{1000}{60 A B} t\left(\text { Temp }_{\text {oil }}-100\right)\left[\frac{1}{l_{2}-l_{1}}\left(e^{-\frac{B l_{1}}{10}}-e^{-\frac{B l_{2}}{10}}\right)+\right. \\
& \frac{1}{h_{2}-h_{1}}\left(e^{-\frac{B h_{1}}{10}}-e^{-\frac{B h_{2}}{10}}\right)+\frac{1}{w_{2}-w_{1}}\left(e^{-\frac{B w_{1}}{10}}-e^{-\frac{B w_{2}}{10}}\right)
\end{aligned}
$$

Parameters $A$ and $B$ were estimated from the moisture data published in (3). For a 'fry' with dimensions $45 \mathrm{~mm}$ x $7.5 \mathrm{~mm} \times 7.5 \mathrm{~mm}(\mathrm{~L} \times \mathrm{H} \mathrm{x} \mathrm{W})$, the estimates were $A=654.2 \pm 13.6$ and $B=9.3$ (indeterminate error) respectively. The fit of the model to the experimental data is excellent (Figure 2).

Furthermore, using the model of Equation 6, the moisture content in the corner of a potato strip could be calculated and compared against other segments of the 'fry' (e.g. center, side, etc). For fries dipped in $0.5 \%$ glucose solution and with initial moisture content of $62.7 \%$, a corner section (Section A) with coordinates in $\mathrm{mm}\left(\mathrm{l}_{1}=0, \mathrm{l}_{2}=0.5\right)\left(\mathrm{h}_{1}=0, \mathrm{~h}_{2}=0.5\right)\left(\mathrm{w}_{1}=0, \mathrm{w}_{2}=0.5\right)$ (Figure 1), i.e. $\mathrm{V}=0.125 \mathrm{~mm}^{3}$, the moisture content after 2 min of frying was estimated as $15.0 \%$. In a side section (Section B) of the 'fry' with co-ordinates $\left(l_{1}=0, l_{2}=0.5\right)$ $\left(\mathrm{h}_{1}=1, \mathrm{~h}_{2}=1.5\right)\left(\mathrm{w}_{1}=0, \mathrm{w}_{2}=0.5\right)$, i.e. same volume as the previous section, the moisture content after 2 min of frying was estimated as $24.6 \%$. Also, a section closer to the center of the 'fry' (Section $\mathrm{C}$ ) with the same volume and with coordinates $\left(\mathrm{l}_{1}=2.0, \mathrm{l}_{2}=2.5\right)\left(\mathrm{h}_{1}=8.0, \mathrm{~h}_{2}=8.5\right)\left(\mathrm{w}_{1}=1.0, \mathrm{w}_{2}=1.5\right)$, had an estimated moisture of $53.9 \%$. The moisture model estimates lower moisture content for 
sections of the 'fry' with higher 'corner effect'. Section A has three sides in contact with oil; the heat is transferred rapidly, the temperature increases rapidly to $100{ }^{\circ} \mathrm{C}$, water is lost and the temperature increases close to that of the oil temperature. Section B has two sides in contact with oil, the heat transfer is slower than in Section A so the temperature will reach $100^{\circ} \mathrm{C}$ later than in Section A. Section $C$ is at the core of the fry where the temperature rise takes place at a slower rate than in Sections A and B, which results in less loss of moisture.
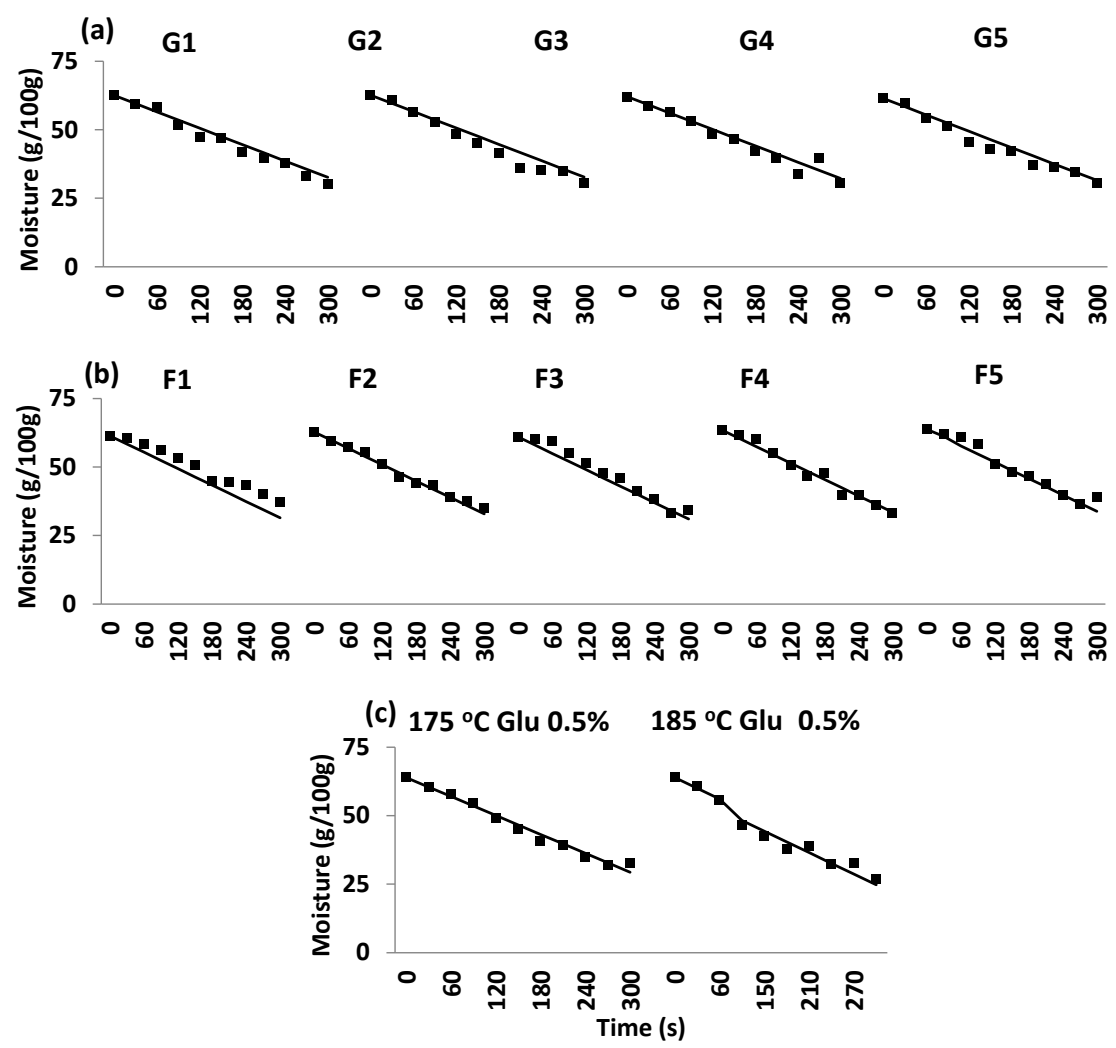

Figure 2. Fit of model predictions to the experimental moisture data. All data derive from (3). Symbols (口) are the experimental data points and the line (---) shows the predictions of the new moisture model. All frying temperatures were $165^{\circ} \mathrm{C}$ unless otherwise stated. 


\section{Modelling acrylamide formation}

The chemistry of acrylamide formation in a food system is complex and the proposed mechanism consists of two distinct pathways: the "generic amino acid" pathway and the "specific amino acid" pathway (3). In the former, the reactive intermediates (e.g. dicarbonyls, hydroxycarbonyls), that are formed during the initial and intermediate stages of the Maillard reaction, react with the asparagine present in the food system to form Schiff bases which, after decarboxylation, dehydration and other reactions, degrade to acrylamide. In the "specific amino acid" pathway, a reducing sugar reacts directly with asparagine to form the corresponding imine which, after decarboxylation, dehydration and a series of other reactions degrades to acrylamide.

Several kinetic mechanisms were devised and tested in an effort to distinguish the generic and the specific amino acid pathways and estimate the corresponding reaction rate constants with a higher degree of accuracy. However, having information only on the concentration of acrylamide and its initial precursors (i.e. free amino acids and sugars), it was not possible for the modelling software to separate the two pathways. Some research groups (5-6) tried to distinguish and model the two pathways in simple aqueous model systems by measuring acrylamide and melanoidins (colored Maillard end products). The models were good, but acrylamide was presumed to be formed entirely via the specific amino acid pathway and the melanoidins were formed exclusively from the generic amino acid pathway

In order to tackle this problem, it was decided to merge the two pathways (i.e. generic and specific). A plausible mechanism was initially proposed by Wedzicha, et al. (7), who established a kinetic model which described the acrylamide formation during heating of rye, wheat and potato cakes. Based on this study, Parker, et al. (3) proposed a similar kinetic mechanism and suggested a model (Kinetic Mechanism 2.0, Figure 3a) which described adequately the formation of acrylamide in French fries with variable glucose and fructose content. 

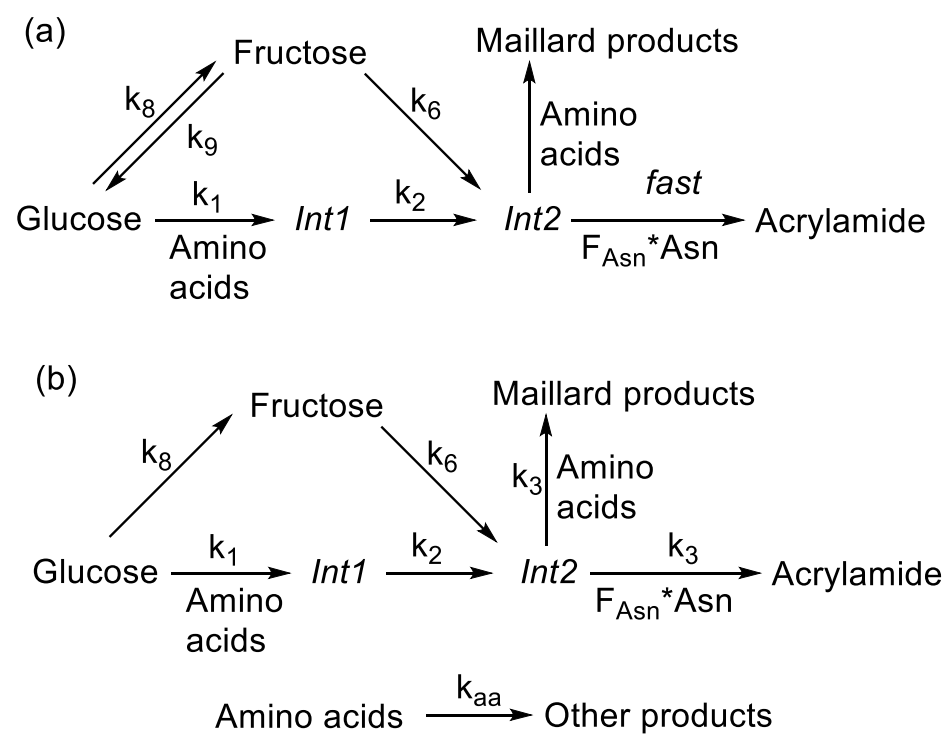

Figure 3. (a) Postulated Kinetic Mechanism 2.0, adapted from (3) which was modified to (b) Kinetic Mechanism 2.1

According to this mechanism, the reaction of glucose with free amino acids proceeds through a two-step kinetic pathway where a first group of intermediates Intl react further to a second pool of key intermediates Int2. This two-step process for glucose has been applied successfully in several models which describe the Maillard reaction with respect to the formation of melanoidins (8), Strecker aldehydes (9) and pyrazines (10). Furthermore, fructose is converted to Int 2 through a one-step process which does not involve free amino acids since their concentration does not show any significant kinetic effect on the rate of the reaction of fructose (8). The pool of intermediates Int2 reacts rapidly to form acrylamide or Maillard reaction products; the concentration of the latter compounds is proportional to the parameters $R$ and $F_{A s n}$, where $R$ is the ratio of asparagine to the total amino acids and $F_{A s n}$ is the proportion of the available asparagine that is converted to acrylamide. The model by Parker, et al. (3) (Figure 3a) was revisited and was altered so as to improve the predictive power in relation to the kinetics of the reactions involving free amino acids. Thus, by hypothesis, an extra rate constant $k_{3}$ was added and the corresponding kinetic mechanism was changed to that of Figure $3 \mathrm{~b}$ (Kinetic Mechanism 2.1), where Int2 reacts with asparagine and the other free amino acids to form acrylamide and other Maillard products respectively. Another advantage of this new approach was that asparagine was incorporated as an extra response to the model. Additionally, an extra first order reaction with 
rate constant $k_{a a}$ was also included to the updated mechanism. It accounted for the amino acid consumption that takes place in the system before the formation of Int2 (10). Furthermore, preliminary tests indicated that the isomerization of glucose to fructose (as expressed by rate constant $k_{9}$, Figure $3 \mathrm{a}$ ) is kinetically insignificant and could be removed. The set of differential equations that comprise the new model (Kinetic Mechanism 2.1, Figure 3b) is given in equations 7-14.

$$
\begin{aligned}
& \frac{d[\text { Glu }]}{d t}=-k_{1}[\text { Glu }][A A s]-k_{8}[\text { Glu }] \\
& \frac{d[\text { Fru }]}{d t}=-k_{6}[\text { Fru }]+k_{8}[G l u] \\
& \frac{d[\text { AAs }]}{d t}=-k_{3}[\text { Int } 2][A A s]-k_{a a}[\text { AAs }] \\
& \frac{d[\text { Asn }]}{d t}=-k_{3}[\text { Int } 2][\text { Asn }]-k_{a a}[\text { Asn }] \\
& \frac{d[\text { Acr }]}{d t}=k_{3}[\text { Int } 2][\text { Asn }] F_{A s n} \\
& \frac{d[\text { MP }]}{d t}=k_{3}[\text { Int }][\text { AAs }]+k_{3}[\text { Int } 2][\text { Asn }]\left(1-F_{\text {Asn }}\right) \\
& \frac{d[\text { Int } 1]}{d t}=k_{1}[\text { Glu }][\text { AAs }]-k_{2}[\text { Int } 1] \\
& \frac{d[\text { Int2 }]}{d t}=k_{6}[\text { Fru }]+k_{2}[\text { Int } 1]-k_{3}[\text { Int } 2][\text { AAs }]
\end{aligned}
$$

The equations were modified to include the temperature and the moisture gradient as they are expressed by Equations 1 and 6, respectively. Furthermore, the reparametrized Arrhenius equation and the activation energy Ea were also introduced (28). In this paper, except if otherwise stated, a universal value for the activation energy $\left(\mathrm{E}_{\mathrm{a}}\right)$ of $100 \mathrm{~kJ} \mathrm{~mol}^{-1}$ was applied to all models. The following example demonstrates how the above conversions were implemented in the modelling procedure.

The hypothetical rate equation (15)

$\frac{d[G l u]}{d t}=-k[G l u][A A s]$

expresses the rate of change of glucose as a second order reaction. With the incorporation of the temperature gradient and the reparametrized Arrhenius equation, the unidimensional expression for the volume bounded by co-ordinates $\left(\mathrm{l}_{1}, \mathrm{l}_{2}\right)\left(\mathrm{h}_{1}, \mathrm{~h}_{2}\right)\left(\mathrm{w}_{1}, \mathrm{w}_{2}\right)$ (Figure 1) with respect to the $x$ axis will become (Equation 16)

$\frac{d[G l u]_{x}}{d t}=-\frac{1}{l_{2}-l_{1}} \int_{l_{1}}^{l_{2}} k_{r e f}[G l u][A A] e^{\frac{E_{a}}{R T}\left(1-\frac{T_{r e f}}{T(x, t)}\right)} d x$ 
where $T(x, t)$ is expressed by Equation 1 which applies along the $x$ axis. Similarly, for the $y$ and $\mathrm{z}$ axis, equations 17 and 18 apply:

$\frac{d[G l u]_{y}}{d t}=-\frac{1}{h_{2}-h_{1}} \int_{h_{1}}^{h_{2}} k_{r e f}[G l u][A A] e^{\frac{E_{a}}{R T r e f}\left(1-\frac{T_{r e f}}{T(y, t)}\right)} d y$
$\frac{d[G l u]_{z}}{d t}=-\frac{1}{w_{2}-w_{1}} \int_{w_{1}}^{w_{2}} k_{r e f}[G l u][A A] e^{\frac{E_{a}}{R T r e f}\left(1-\frac{T_{r e f}}{T(z, t)}\right)} d z$

where $T(y, t)$ and $T(z, t)$ are expressed by Equation 1 for the $y$ and $z$ axis respectively.

The total rate of change of glucose concentration is approximated by equation 19:

$\frac{d[G l u]_{t o t}}{d t} \approx \frac{d[G l u]_{x}}{d t}+\frac{d[G l u]_{y}}{d t}+\frac{d[G l u]_{z}}{d t}$

Furthermore, the effect of moisture content $(M)$ was accounted by multiplying the concentration of each analyte with the term $(1-M)$ where $M$ is the moisture content.

Hence, the final expression for the rate of change of glucose is to a first approximation given by Equation 20.

$\frac{d[G l u]_{t o t}}{d t} \approx-k_{\text {ref }}[G l u][A A](1-M)^{2}\left[\frac{1}{l_{2}-l_{2}} \int_{l_{1}}^{l_{2}} e^{\frac{E_{a}}{R T}\left(1-\frac{T_{r e f}}{T(x, t)}\right)} d x+\right.$
$\left.\frac{1}{h_{2}-h_{2}} \int_{h_{1}}^{h_{2}} e^{\frac{E_{a}}{R T}\left(1-\frac{T_{r e f}}{T(y, t)}\right)} d y+\frac{1}{w_{2}-w_{1}} \int_{w_{1}}^{w_{2}} e^{\frac{E_{a}}{R T}\left(1-\frac{T_{r e f}}{T(z, t)}\right)} d z\right]$

where: $\mathrm{k}_{\mathrm{ref}}$ is the reaction rate constant at the reference temperature, $[G l u]$ is the defatted dry weight concentration of glucose, $[A A]$ is the defatted dry weight total concentration of the free amino acids, $M$ is the moisture content, $E_{a}$ is the activation energy, $R$ is the universal gas constant, $T_{r e f}$ is the reference temperature in $\mathrm{K}$ (in our study it is $165^{\circ} \mathrm{C} \equiv 438 \mathrm{~K}$ ) and $T$ is the process temperature in $\mathrm{K}$.

Multiresponse kinetic modelling was performed for Kinetic Mechanism 2.1 (Figure 3bError! Reference source not found.) using the software Athena Visual Studio. The model parameters were estimated by minimizing the sum of squares according to the determinant criterion (11). Modelling was performed using the dataset from the study of Parker, et al. (3), however, in the current 
study we employed the revised kinetic model and heat and moisture transport equations as was demonstrated in the example above. The optimal estimates for the parameters and their $95 \%$ highest posterior density intervals are presented in Table 1.

Table 1. Parameter estimates for the Kinetic Model 2.1 (Figure 3b).

\begin{tabular}{lcl}
\hline \multicolumn{1}{c}{ Parameter } & $\begin{array}{c}\text { Optimal } \\
\text { estimate } \times 10^{4}\end{array}$ & \multicolumn{1}{c}{$\begin{array}{c}\text { 95\% Confidence } \\
\text { interval } x 10^{4}\end{array}$} \\
\hline $\mathrm{k}_{1}\left(\mathrm{mmol}^{-1} \mathrm{~kg} \mathrm{~s}^{-1}\right)$ & 0.7 & $\pm 0.08(12 \%)$ \\
$\mathrm{k}_{2}\left(\mathrm{~s}^{-1}\right)$ & 937 & $\pm 366(39 \%)$ \\
$\mathrm{k}_{3}\left(\mathrm{mmol}^{-1} \mathrm{~kg} \mathrm{~s}^{-1}\right)$ & 42300 & $\pm 14870(35 \%)$ \\
$\mathrm{k}_{6}\left(\mathrm{~s}^{-1}\right)$ & 80 & $\pm 5(7 \%)$ \\
$\mathrm{k}_{8}\left(\mathrm{~s}^{-1}\right)$ & 27 & $\pm 7.7(28 \%)$ \\
$\mathrm{k}_{\text {aa }}\left(\mathrm{s}^{-1}\right)$ & 19 & $\pm 7.6(39 \%)$ \\
$\mathrm{F}_{\text {Asn }}$ & 64 & $\pm 4.7(7 \%)$ \\
\hline
\end{tabular}

The model parameters are reliable since their statistical error is low. The value of the rate constant $k_{a a}$ was estimated as $19 \times 10^{-4} \mathrm{~s}^{-1}$ which demonstrates that there is another route for amino acid consumption. Inclusion of this particular rate constant in the model improved the fit of the model with regard to the total amino acids concentration (not shown). The rate constant $k_{3}$ has a very high value compared to the other rate constants which suggests that this step proceeds relatively quickly as has been implied in other studies $(3,9)$. This is confirmed by model simulation based on the above parameters: Int 2 has the typical behavior of an intermediate which reacts rapidly to other compounds, as soon as it is formed. Consequently, the reactions which are described by the rate constants $\mathrm{k}_{1}, \mathrm{k}_{2}$ and $\mathrm{k}_{6}$ control the acrylamide formation. The fit of the model to the experimental values was very good. For asparagine in particular, the corresponding fit is demonstrated in Figure 4. 

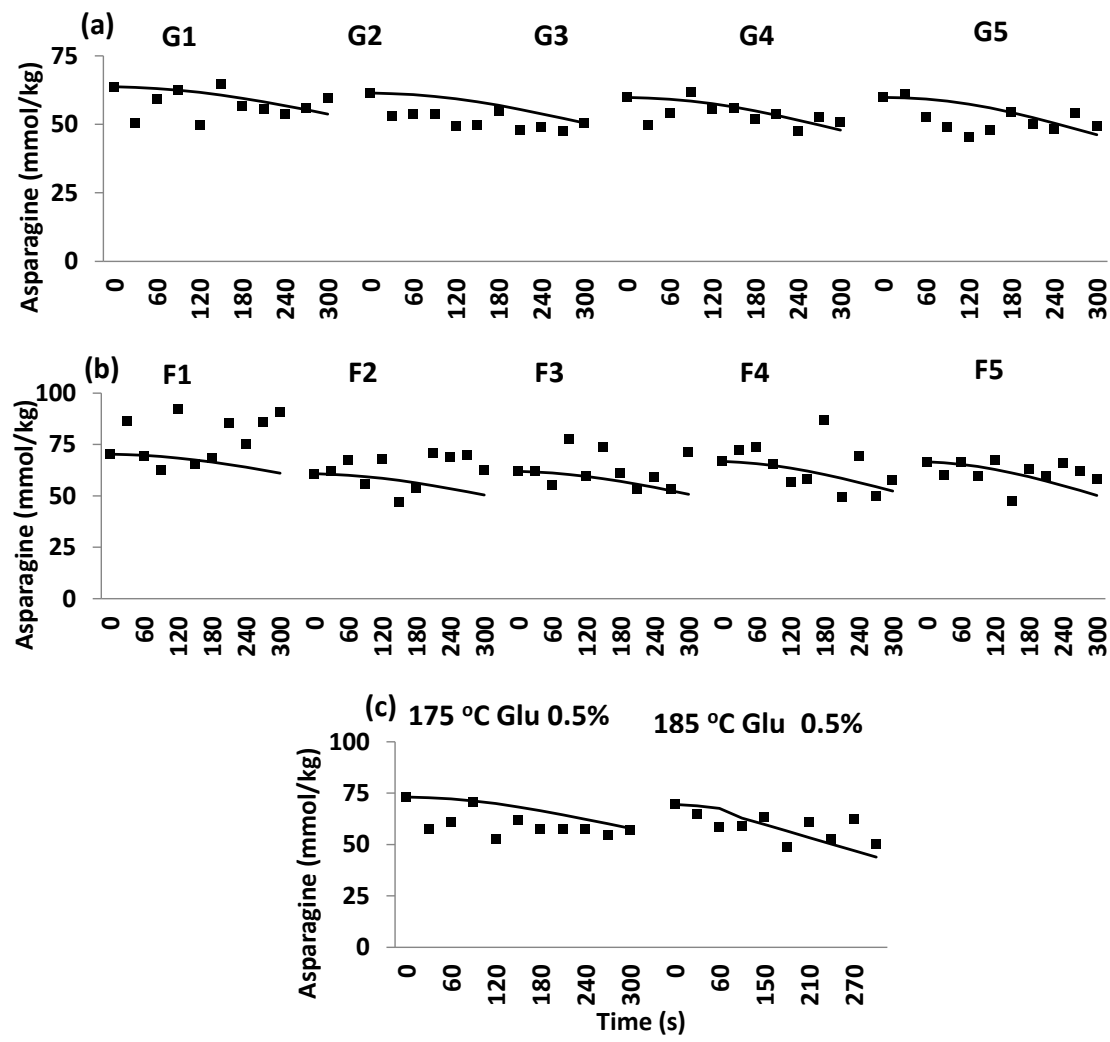

Figure 4. Fit of the model predictions to the experimental data for asparagine. All data derive from the experiment of Parker, et al. (3). Symbols (口) are the experimental data points and the line (---) shows the predictions of the moisture model. Frying temperatures were $165^{\circ} \mathrm{C}$ unless otherwise stated.

Using Kinetic Model 2.1 with the parameter estimates of Table 1, we can run model simulations and predict the concentrations of the compounds of interest in various areas of the fries. For a 'fry' dipped in $0.5 \%$ glucose solution and with initial moisture content $62.7 \%$, the concentration of the key compounds of this study at three different sections (A, B, and C) of the 'fry' after 2 minutes of frying at $165^{\circ} \mathrm{C}$ were estimated as in Table 2 . 
Table 2. Estimates from Kinetic Model 2.1 for the concentration of acrylamide and its key precursors, at three different locations in French fries", fried at $165^{\circ} \mathrm{C}$ for 2 minutes.

\begin{tabular}{lccc}
\hline $\begin{array}{c}\text { Compound name } \\
\text { (concentration) }\end{array}$ & $\begin{array}{c}\text { Section A } \\
\text { (corner) }\end{array}$ & $\begin{array}{c}\text { Section B } \\
\text { (edge) }\end{array}$ & $\begin{array}{c}\text { Section } \\
\text { C (core) }\end{array}$ \\
\hline Glucose $(\mathrm{mmol} / \mathrm{kg})$ & 0.18 & 0.9 & 26 \\
Fructose $(\mathrm{mmol} / \mathrm{kg})$ & 2.3 & 4.7 & 13 \\
Total AAs $(\mathrm{mmol} / \mathrm{kg})$ & 8.5 & 101 & 172 \\
Asparagine $(\mathrm{mmol} / \mathrm{kg})$ & 30 & 36 & 61 \\
Acrylamide $(\mu \mathrm{mol} / \mathrm{kg})$ & 85 & 78 & 5.3 \\
\hline
\end{tabular}

*the par-fried potato strips were dipped in a $2 \%$ glucose solution and had $62.7 \%$ initial moisture content

The simulations were applied for a corner section (Section A) with coordinates in $\mathrm{mm}\left(\mathrm{l}_{1}=0.0, \mathrm{l}_{2}=0.5\right)\left(\mathrm{w}_{1}=0.0, \mathrm{w}_{2}=0.5\right)\left(\mathrm{h}_{1}=0.0, \mathrm{~h}_{2}=0.5\right)$ (Figure 1) i.e. $\mathrm{V}=0.125 \mathrm{~mm}^{3}$, a side section (Section $\mathrm{B}$ ) of the 'fry' with co-ordinates $\left(\mathrm{l}_{1}=0.0\right.$, $\left.\mathrm{l}_{2}=0.5 \mathrm{~mm}\right)\left(\mathrm{w}_{1}=1.0, \mathrm{w}_{2}=1.5 \mathrm{~mm}\right)\left(\mathrm{h}_{1}=0.0, \mathrm{~h}_{2}=0.5 \mathrm{~mm}\right)$, i.e. some volume as the corner part, and finally a more central section (Section $C$ ) of the 'fry' of the same volume $\left(0.125 \mathrm{~mm}^{3}\right)$ with co-ordinates $\left(l_{1}=8.0, l_{2}=8.5 \mathrm{~mm}\right) \quad\left(\mathrm{w}_{1}=1.0\right.$, $\left.\mathrm{w}_{2}=1.5 \mathrm{~mm}\right)\left(\mathrm{h}_{1}=2.0, \mathrm{~h}_{2}=2.5 \mathrm{~mm}\right)$.

The predictions made by Kinetic Model 2.1 demonstrate that the model can account successfully for the corner effects. The corner segments of the fry are more exposed to the heat transfer medium; the temperature rises faster, more moisture is lost, the reactants become more concentrated, the rate constants increase, the rates of reactions increase, resulting a faster/greater depletion of precursors and hence faster/greater formation of acrylamide. So, as calculated above, the corner section (Section A) will have higher concentration of acrylamide than the side section (Section B), since the former has three sides in direct contact to the hot oil, while the latter only two. The central section (Section C) of the fry has the least acrylamide content since it is furthest away from the hot oil, the temperature rises slower and moisture is retained for longer.

An enhanced modelling procedure that takes into account the heat and mass transfer phenomena on the three dimensional space has been demonstrated in this paper. Kinetic Model 2.1 suggests that the first kinetic steps of the reactions of glucose and fructose limit the formation of acrylamide. The high rate of the reaction described by $k_{3}$ confirms that the corresponding step proceeds faster than the others in Maillard reaction. 


\section{References}

1. Balagiannis, D. P., Predicting aroma formation with kinetic models. In Flavour Development, Analysis and Perception in Food and Beverages, Parker, J. K.; Elmore, J. S.; Methven, L., Eds. Woodhead Publishing: 2015; pp 211-233.

2. Parker, J. K., The kinetics of thermal generation of flavour. J. Sci. Food Agric. 2013, 93, 197-208.

3. Parker, J. K.; Balagiannis, D. P.; Higley, J.; Smith, G.; Wedzicha, B. L.; Mottram, D. S., Kinetic Model for the Formation of Acrylamide during the Finish-Frying of Commercial French Fries. J. Agric. Food Chem. 2012, 60, 9321-9331.

4. Ni, H.; Datta, A. K., Moisture, Oil and Energy Transport During DeepFat Frying of Food Materials. Food Bioprod Process 1999, 77, 194-204.

5. De Vleeschouwer, K.; Van der Plancken, I.; Van Loey, A.; Hendrickx, M. E., The kinetics of acrylamide formation/elimination in asparagine-glucose systems at different initial reactant concentrations and ratios. Food Chem. 2008, $111,719-729$.

6. Knol, J. J.; van Loon, W. A. M.; Linssen, J. P. H.; Ruck, A.-L.; van Boekel, M. A. J. S.; Voragen, A. G. J., Toward a kinetic model for acrylamide formation in a glucose-asparagine reaction system. J. Agric. Food Chem. 2005, 53, 6133-6139.

7. Wedzicha, B. L.; Mottram, D. S.; Elmore, J. S.; Koutsidis, G.; Dodson, A. T., Kinetic models as a route to control acrylamide formation in food. $A d v$. Exp. Med. Biol. 2005, 561, 235-253.

8. Mundt, S.; Wedzicha, B. L., A Kinetic Model for the Glucose-Fructose-Glycine Browning Reaction. J. Agric. Food Chem. 2003, 51, 3651-3655.

9. Balagiannis, D. P.; Parker, J. K.; Pyle, D. L.; Desforges, N.; Wedzicha, B. L.; Mottram, D. S., Kinetic modeling of the generation of 2- and 3methylbutanal in a heated extract of beef liver. J Agric Food Chem 2009, 57, 9916-22.

10. Low, M. Y. Relationship between acrylamide formation and flavour generation in heated foods. PhD Thesis, University of Reading, Reading, 2006.

11. van Boekel, M. A. J. S., Multiresponse Kinetic Modeling of Chemical Reactions. In Kinetic Modeling of Reactions In Foods, CRC Press: 2008. 